\title{
Going up...?
}

Optimistic futurists suggest that we'll have a working space 'elevator' in just a few decades. Solarpowered cars ferrying satellites and materials for space exploration will run up and down a tube-like tether some 50,000 km long, stretched between Earth and an orbiting space station. Maybe. Then again, we may one day look back at the idea as we now do past visions of flying cars and moon colonies, predicted to be routine by 2001 .

But other, less dramatic schemes involving space may well help us to do some imaginative physics. Today's state-of-the-art experiments in twodimensional turbulence - relevant to real-world flows, especially in oceans and planetary atmospheres, for example - rely on soapy films and shallow liquids. We might do much better with vast liquid films floating in space.

That, at least, is what physicists Rui Zheng and Tom Witten of the University of Chicago have been suggesting for a couple of years now. They envisage a fluid roughly $1 \mu \mathrm{m}$ thick in a circular layer about $1 \mathrm{~km}$ across, held in a lightweight frame. Keeping the film stable in the harsh space environment, and for long enough to do useful experiments, may not be as difficult as one might imagine.

An ordinary low-viscosity fluid, such as soapy water, would evaporate almost instantaneously in space. A suitable fluid must have both low viscosity, being thereby suited to generating flows with high Reynolds numbers, and an exceedingly small vapour pressure. Remarkably, as Zheng and Witten point out, a fluid that comes close can be found off the shelf - Dow Corning 705 diffusion pump oil.

Even at about $300 \mathrm{~K}$ - the likely temperature of a film in thermal equilibrium, under exposure to sunlight - this oil (actually, a modified cousin of this oil with slightly higher molecular weight) could easily remain for as long as a year before evaporating. Keeping the oil from freezing is equally important, and demands that its orbit not pass through the Earth's shadow. More subtly, the film could be destroyed by ordinary thermal fluctuations, but this doesn't seem to be a serious problem either. Calculations suggest that a coating of surfactant could stabilize the film for 100 years.

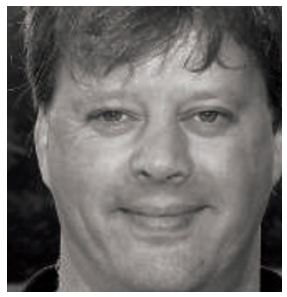

But there is a more serious obstacle - bombardment by micrometeorites. Although tiny meteorites may well pass through the film, Zheng and Witten estimate that any particle with radius larger than about $1 \mu \mathrm{m}$ will be 'dangerous' to the film, in the sense of being able to punch out We might a hole large enough to persist and do some imaginative physics with vast liquid films floating in space. begin growing, ultimately leading to the film's collapse.

Unfortunately, data suggest that a film $1 \mathrm{~km}$ in diameter would be hit about 100 times per second by particles of the dangerous kind. So a film experiment, in the absence of any nifty engineering of 'self-healing' properties in the fluid, will probably require significant shielding.

That makes the project much more difficult. But the pay-off, in physics terms, could be considerable, including an increase in achievable Reynolds numbers by three to four orders of magnitude. There is also, of course, the tricky matter of getting all the materials up into space in the first place unless, of course, we can use that space elevator.

Mark Buchanan

\section{Looking back}

Modern science can reasonably be said to have come into being during the time of Queen Elizabeth I of England. While William Shakespeare was composing sonnets, in Italy Galileo Galilei was developing the idea that careful experiments in a laboratory could reveal universal truths about the way objects move through space. Later, hearing about the newly invented telescope, he made one for himself and with it made discoveries that astonished and thrilled all of Europe. Nevertheless, in 1633, Galileo was put on trial for his scientific teachings.

Another great scientist of the day, William Harvey, who discovered the circulation of the blood, worked not only at the same time as Galileo, but even at the same place - the University of Padua. Touring the old university campus at the heart of the city, one is shown Galileo's cattedra, the wooden pulpit from which he lectured, and, curiously, one of his vertebrae in a display case just outside the rector's office (maybe the rector needs to be reminded to have a little spine). You can also see the lecture theatre in which Harvey dissected cadavers, while eager students peered down from tiers of balconies. Such dissections were illegal in Harvey's time, so the floor of the theatre was equipped with a mechanism to make the body disappear when a lookout gave the signal that the authorities were coming.

Another important player in the same era was not a scientist at all, but a lawyer who rose to be Lord Chancellor of England

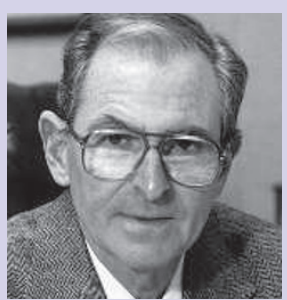

Sir Francis

Bacon put forward the first theory of the scientific method. in the reign of King James I, Elizabeth's successor. His name was Sir Francis Bacon, and in his magnum opus, Novum Organum, he put forward the first theory of the scientific method. In Bacon's view, the scientist should be a disinterested observer of nature, collecting observations with a mind cleansed of harmful preconceptions that might cause error to creep into the scientific record. Once enough such observations have been gathered, patterns will emerge, giving rise to truths about nature.

But even in Bacon's time there were those who knew better. "That's exactly how a Lord Chancellor would do science", William Harvey is said to have grumbled.

David Goodstein 